\title{
The relation between the just readable threshold of Chinese characters of various styles and adaptation luminance
}

\author{
Koichi IKEDA* Koji NODA** Kiyoshige OBARA* \\ Shoichiro YAMAGUCHI***
}

The purpose of this study is to investigate the just readable threshold of Chinese characters of different styles as a function of the adaptation luminance. The test objects are 44 Chinese characters comprising from 2 to 19 elements from among those most frequently appearing in news papers and the styles of which are Gothic, Ming, semi-cursive and penwritten square, in daily use. The observers are of all normal vision, and the just readable threshold coressponding to $\mathbf{5 0} \%$ threshold is used.

Results obtained are as follows.

(1) The relation between the just readable threshold by style and adaptation luminance are approximated by following formulas:

Gothic style:

Ming style:

Semi-cursive style:

Pen-written style:

$$
\begin{aligned}
& \theta=\frac{3.514\left(0.3394+L^{1 / 4}\right)^{4}}{L} \text { (minutes) } \\
& \theta=\frac{3.590\left(0.3485+L^{1 / 4}\right)^{4}}{L} \text { (minutes) } \\
& \theta=\frac{3.721\left(0.3528+L^{1 / 4}\right)^{4}}{L} \text { (minutes) } \\
& \theta=\frac{3.815\left(0.3978+L^{1 / 4}\right)^{4}}{L} \text { (minutes) }
\end{aligned}
$$

where $\theta$ is the visual angle (minutes) of the character's height at the just readable threshold, and $L$ is the adaptation luminance $\left(\mathrm{cd} / \mathrm{m}^{2}\right)$.

(2) Comparison between above formulas and approximate curve of minimum angle of resolution of the break width of the Landolt ring shows that the line width of the Gothic styles at the threshold are considerable lower than those estimated from the visual acuity.

The heights of the characters measured in terms of visual angle at the threshold are 9.2 times as large for Gothic, 9.5 times for Ming, 10 times for semi-cursive and 11 times for pen-written square as that of break width of Landolt rings.

(3) To recognize a Chinese character, first of all it must be of a certain size, and the line composing the character must be a certain width in order to distinguish the details, from the correspondence with the approximate curve of visual acuity.

\section{Introduction}

It is known that when a person is performing a visual task in a visual environment the illumination level or the brightness of the visual object affects the viewing time, fatigue and rate of error. If the visual environment is correctly prepared, the visual task can be performed efficiently. As for the levels of illumination for specifying the environment, at present there are the recommended levels of illumination in the Japanese Industrial

* Faculty of Science and Engineering, Science University of Tokyo.

** TL Yamagiwa Laboratory Inc.

*** Faculty of Engineering, Tokyo Institute of Technology.

A part of this paper WAS described in Reference (1) $\sim(3)$ and $(6)$.
Standards (JIS). However, it is difficult to say whether these levels always correspond to the human ability to recognize objects.

Previously, we performed research on the relation between the adaptation luminance and the visual acuity, and studied the relation between the brightness level and the human ability to recognize objects. In order to render these relations more practical, we believe that it is necessary to clarify the relation between the brightness level and the ability to recognize letters. In this study we performed visual experiments using Chinese characters of different styles, and studied the changes in the just readable threshold resulting from differences in style and the relation between the adaptation luminance and the just readable threshold, and also examined their correspondence to visual acuity. 


\section{Conditions of visual experi- ments}

\subsection{Characters as visual objects used in visual experiments}

There are various styles of Chinese characters in daily use. For example, in printed matter, the Ming and Gothic styles are the most frequently used. In handwriting there are the pen-written square, semi-cursive and cursive styles, etc. The ease of reading and the impression created by the written characters depend upon the style, and we believe that the number of elements composing a character also affects the ease of reading.

In this study, we adopted the styles in daily use, such as Gothic, Ming, semi-cursive and pen-written square, as the visual objects. We selected $44 \mathrm{Chi}$ nese characters comprising from 2 to 19 elements from among those most frequently appearing in newspapers. By the number of elements we mean the number of straight lines, curves and points composing a character, so it may occasionally differ from the number of strokes used to write the character. Table 1 shows the frequency of use

Table 1 Frequency of selected characters and number of elements.

\begin{tabular}{|c|c|c|c|}
\hline $\begin{array}{c}\text { numbers } \\
\text { elements } \\
\text { ele }\end{array}$ & frequency of use & $\begin{array}{l}\text { number } \\
\text { elements }\end{array}$ & frequency of use \\
\hline $\begin{array}{c}\frac{\text { elements }}{\text { below }} \\
4\end{array}$ & 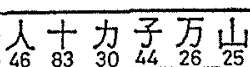 & 12 & 後建業貴害 \\
\hline 5 & 代円未 & 13 & 亳都鉄援 \\
\hline 6 & $\frac{1}{30}$ & 14 & 開場組健 \\
\hline 7 & 出百 & 15 & 䦔 \\
\hline 8 & 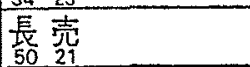 & 16 & 電関 暴 \\
\hline 9 & 繋者 & 17 & 築 \\
\hline 10 & $\begin{array}{l}\text { 前省明 } \\
30\end{array}$ & 18 & 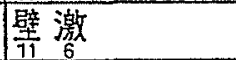 \\
\hline 11 & 登悬 & 19 & \begin{tabular}{|l|} 
䋛 \\
12
\end{tabular} \\
\hline
\end{tabular}

of the selected characters and the number of elements. Figure 1 shows an example of the styles of characters used as visual objects. For the Gothic, Ming and semi-cursive styles, we selected the original forms from the Hattai Jikan, a Chinese character dictionary, and for the pen-written style selected the forms from a textbook of penmanship.

As Chinese characters differ in height according

$$
\begin{aligned}
& \text { 子代東員都場間電激 締 } \\
& \text { 子代東員都場間電激 締 } \\
& \text { 子代東員都埸间電激缔 } \\
& \text { 子代東員都場間電激締 }
\end{aligned}
$$

Fig. 1 Sample characters used as visual object. to style, we measured the width of the lines (strokes) of the Gothic Chinese character classification and the height to find the relationship between them. We found that the average height of a character was 10.326 times the line width. Thus defining the height of the Chinese character based on the line width of Gothic style characters, we prepared the Ming and square style characters with an average height equal to that of the Gothic style. Regarding pen-written styles, as the characters differ greatly in height, we did not use any mean values but prepared the visual objects so that the height of each character would be equal to that of the Gothic characters.

From these original forms, we printed the characters on photographic papers and adjusted their height, classifing them into 20 stages ranging from $4 \mathrm{~mm}$ to $81 \mathrm{~mm}$. For our visual objects we made 1,144 sheets per style, a total of 4,576 sheets. The luminance contrast of the visual objects was $92 \%$, which is the value when the photographic paper is fully exposed. We measured the height of all the visual objects with a microscope, and confirmed that discrepancies were less than $3 \%$ of the designed value, which is in conformity with the criteria for visual acuity tests. Figure 2 shows examples of the measured height of the visual objects, while Fig. 3 shows the relative errors between the measured values and the designed values of the visual objects.
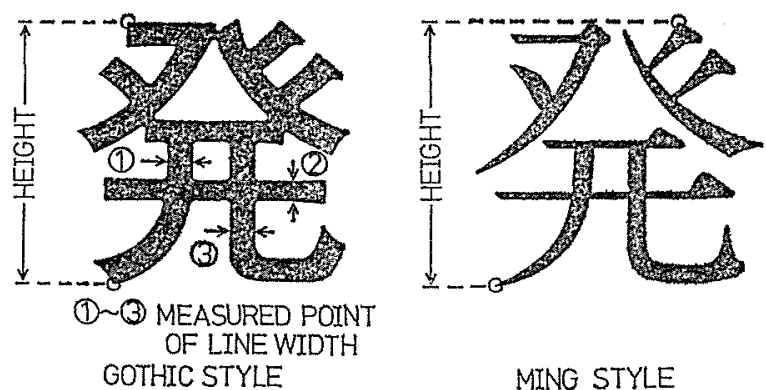

Fig. 2 Measurement of character's height.

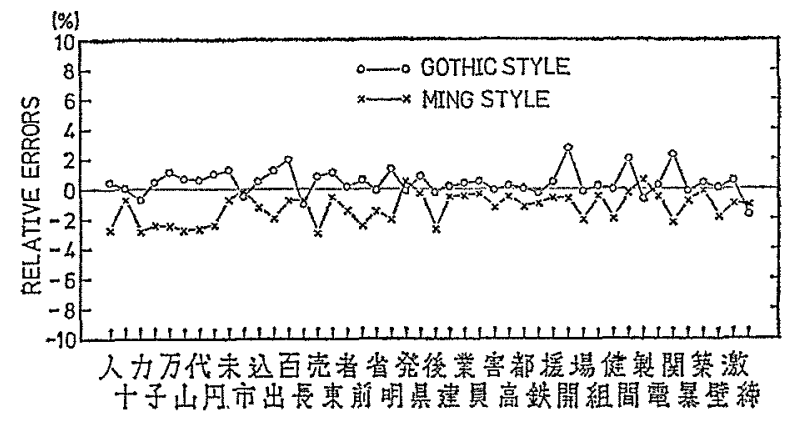

Fig. 3 Relative errors between measured value of visual object and designed one.

\subsection{The room for visud experimenis}

The room for visual experiments is constructed as illustrated in Fig. 4. The left section of the room is the location for experimenters who display 


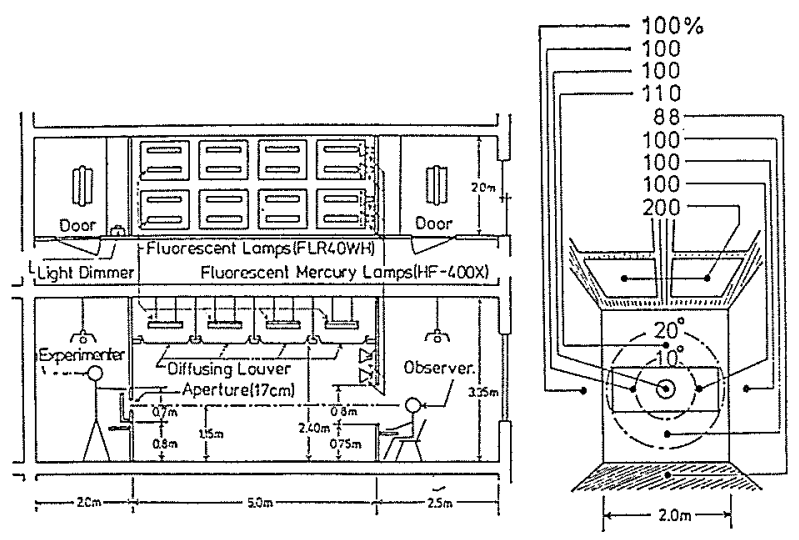

Fig. 4 Visual experimental room.

the test objects through a $17 \mathrm{~cm} \phi$ circular aperture equipped on the partition wall. The height of the center of aperture is $1.15 \mathrm{~m}$ from the floor, and the visual angle at an observer's eyes subtended by its diameter is $2^{\circ}$. The middle section provides a space to separate the displayed object from an observer; this space is $2 \mathrm{~m}$ wide, $2.4 \mathrm{~m}$ high, and $5 \mathrm{~m}$ long; the surface of the plane surrounding the displayed test object, the side walls and floor are painted diffusing white. The ceiling of the middle section is wholly covered with white diffusing panel, and then is illuminated from the top by 16 fluorescent lamps so that the whole ceiling is a diffusing light source with uniform luminance. The luminance of the background that covers the visual field of more than $20^{\circ}$ can be varied from 0 to $450 \mathrm{~cd} / \mathrm{m}^{2}$ by controlling the luminous power of these fluorescent lamps by means of a dimmer, and also a higher luminance value up to $5,000 \mathrm{~cd} / \mathrm{m}^{2}$ can be obtained by dimmable fluorescent mercury lamps equipped on the observer-side partition wall. The visual field viewed from the observer's position and its luminance distribution are shown in Fig. 4.

The right section is the space for an observer who sits on a chair to view the test object through a window of $0.8 \mathrm{~m}$ in height and $1.8 \mathrm{~m}$ in width. The observation distance from the observer's eyes to the test object is $5.55 \mathrm{~m}$, in accordance with visual acuity test.

The background luminance of more than $0.1 \mathrm{~cd} /$ $\mathrm{m}^{2}$ is measured by a luminance meter (TOSHIBA $\mathrm{BM}-1$ ), and that of less than $0.1 \mathrm{~cd} / \mathrm{m}^{2}$ is measured by a self-made high sensitivity luminance meter with a photomultiplier as a detector. The adaptation luminance is evaluated by the average luminance of the background which subtends a visual angle of $10^{\circ}$.

\subsection{Method of displaying visual objects}

We performed preparatory experiments for each adaptation luminance, and determined the sizes of the visual objects, ranging from the size at which the visual objects can be fully discriminated to that at which they cannot be recognized at all.
We then obtained our visual objects by selecting all 44 characters between the 8 th to the 12th stages within the above-mentioned range.

We displayed the selected visual objects in random order to the observer, utilizing a table of random digits. In accordance with the criteria for visual acuity tests, we displayed each visual object for 3 seconds at a time and displayed a white sheet for 2 seconds in between each displaying. Table 2 shows the levels of adaptation luminance and the adaptation time, while Fig. 5 shows the flow chart of the experiment. The observer attempted to discriminate the character presented to him, while the experimenter recorded the response. The experiment was performed three times on each observer for each adaptation luminance. That is, 15 times experiments per each adaptation Iuminance.

Table 2 Range of adaptation luminance and time duration of adaptation.

\begin{tabular}{c|c}
$\begin{array}{c}\text { adaptation luminance } \\
\left(\mathrm{cd} / \mathrm{m}^{2}\right)\end{array}$ & $\begin{array}{c}\text { time duration for adaptation } \\
\text { (minutes) }\end{array}$ \\
\hline 1000 & 5 \\
100 & \\
10 & 15 \\
\hline 1 & 30 \\
\hline 0.1 & \\
\hline 0.01 & \\
\hline
\end{tabular}

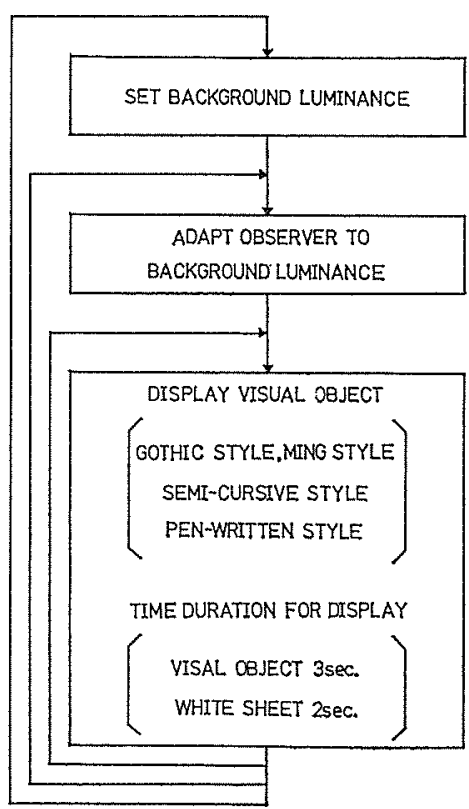

Fig. 5 Flow chart of visual experiment.

\subsection{Observers}

We selected eight male students with normal vision aged from 22 to 24 . Table 3 shows the ages and visual acuities of the observers. 
Table 3 Observers.

\begin{tabular}{c|c|c|c}
\hline experiment & observer & age & $\begin{array}{c}\text { visual } \\
\text { acuity }\end{array}$ \\
\hline \multirow{6}{*}{ I } & K. M. & 22 & 2.0 \\
& M. H. & 23 & 2.0 \\
& O. N. & 24 & 1.5 \\
& N. T. & 24 & 1.2 \\
& K. T. & 23 & 0.8 \\
\hline \multirow{6}{*}{ II } & T. I. & 24 & 2.0 \\
& T.M. & 22 & 1.5 \\
& H. I. & 22 & 1.5 \\
\hline
\end{tabular}

\section{Adaptation luminance and just readable threshold}

\subsection{Calculation of the just readable threhshold}

As shown in Fig. 6, the relation between the probability for the observer to correctly recognize each character and the character's height was plotted on a normal probability graph. The points were connected by regression lines using the least square method for each adaptation luminance, and we obtained the just readable threshold corresponding to the $50 \%$ threshold. The height of the character in this threshold was expressed as a visual angle (minutes) viewed from the position of the observer's eyes.

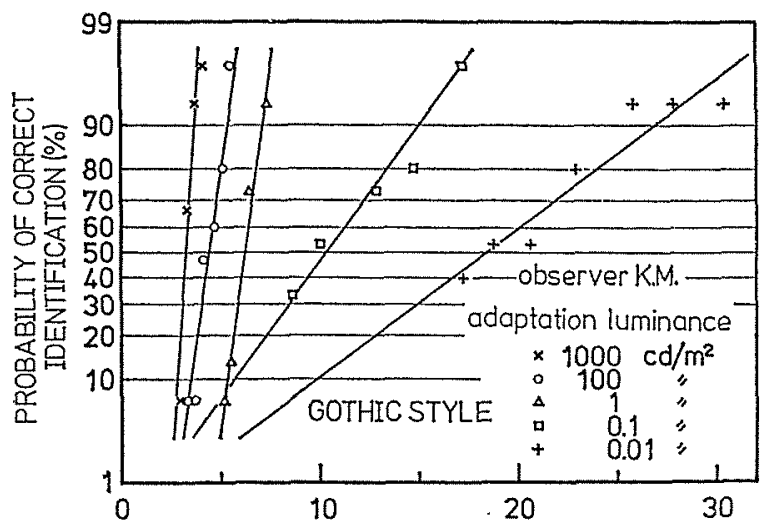

VISUAL ANGLE OF CHARACTER'S HEIGHT (minutes)

Fig. 6 Relation between probability of correct identification and character's height.

\subsection{Number of character's elements and just readable threshold}

Figure 7 shows the relation between the visual angle of character's height and the number of elements making up the character at the just readable threshold for each style. It shows that the increase in the number of elements increases the visual angle of the character's height at the just readable threshold, making reading difficult. Moreover, a decrease in the adaptation luminance also increases the visual angle in the just readable threshold.

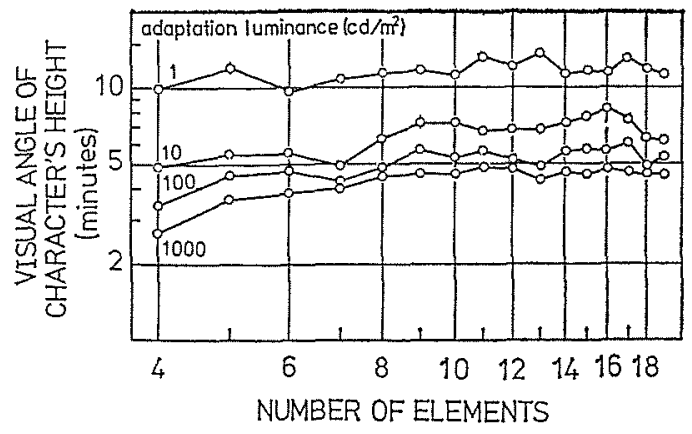

(a) Gothic style

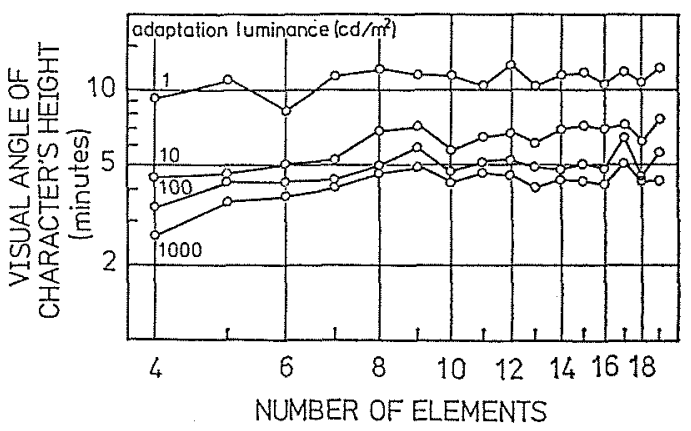

(b) Ming style

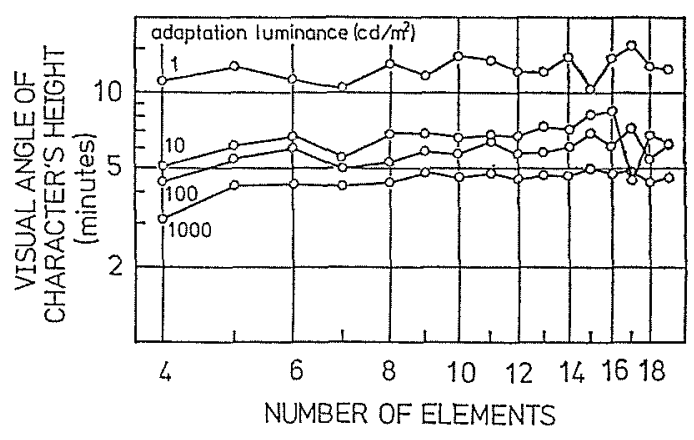

(c) Semi-cursive style

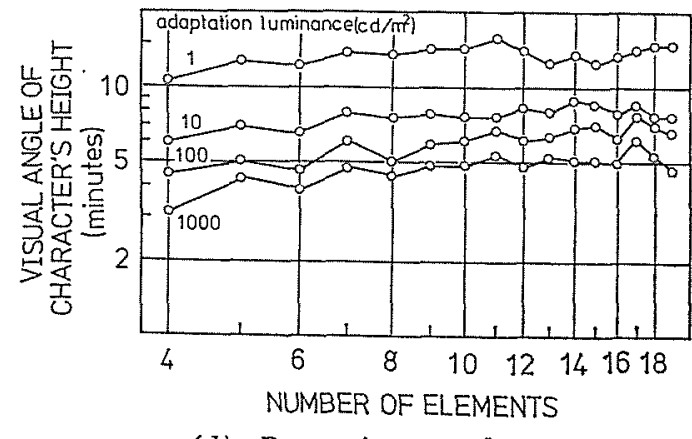

(d) Pen-written style

Fig. 7 Visual angle at just readable threshold and number of elements.

\subsection{Approximate curve at just readable threshold}

To survey the relation between the adaptation luminance and the just readable threshold, we plotted the mean value for the character's height 
in the just readable threshold at the most frequently used number of elements ( 7 to 11) for each writing style against adaptation luminance. We then drew a smooth curve connecting these points by determining coefficients $A$ and $B$ which minimize the square sum of the deviation between the measured values and calculated values using an approximate curve and equation of the following form,

$$
\theta=\frac{A\left(B+L^{1 / 4}\right)^{4}}{L}
$$

where $\theta$ is the visual angle (minutes) in the just redable threshold, and $L$ is the adaptation luminance $\left(\mathrm{cd} / \mathrm{m}^{2}\right)$. However, deviation $\varepsilon$ is expressed by the following formula;

$$
\varepsilon=\frac{\text { (measured value-culculated value) }}{\text { (measured value) }} \text {....(2) }
$$

The approximate formulas for various styles are shown below.

Gothic Style:

$$
\theta=\frac{3.514\left(0.3394+L^{1 / 4}\right)^{4}}{L} \text { (minutes) }
$$

Ming Style:

$$
\theta=\frac{3.590\left(0.3485+L^{1 / 4}\right)^{4}}{L} \text { (minutes) }
$$

Semi-Cursive Style:

$$
\theta=\frac{3.721\left(0.3528+L^{1 / 4}\right)^{4}}{L} \text { (minutes) }
$$

Pen-Written Style:

$$
\theta=\frac{3.815\left(0.3978+L^{1 / 4}\right)^{4}}{L} \text { (minutes) }
$$

where $\theta$ is the visual angle (minutes) of the character's height at the just readable threshold, and $\mathrm{L}$ is the adaptation luminance $\left(\mathrm{cd} / \mathrm{m}^{2}\right)$.

Table 4 shows the deviations between the measured values and the calculated values. Each deviation is held within approximately $\pm 10 \%$.

Furthermore, at adaptation luminances $0.01 \mathrm{~cd} /$ $\mathrm{m}^{2}$ and $0.1 \mathrm{~cd} / \mathrm{m}^{2}$, we obtained the just readable threshold in the Gothic style and Ming style for different observers and made comparisons, taking into consideration the difference in the visual acuities of the observers. As a result, we have concluded that although the deviations from the measured values of the Gothic style in adaptation luminance $0.01 \mathrm{~cd} / \mathrm{m}^{2}$ are large, the values are sufficiently approximate, and there is no problem involved in their practical use.

Table 5 shows coefficients $A$ and $B$ of the approximate curve for the number of elements ranging from 4 to 6,7 to 11 , and 12 to 19 of the various writing styles. Accompanying the increase in the number of elements, there is a tendency for coefficient $A$ to increase, while $B$ decreases. Regardless of the number of elements, coefficient $A$ is larger most in the case of the Gothic style, followed by the Ming, semi-cursive and pen-written square styles in that order. On the other hand, while coefficient $B$ shows the same trend as $A$ when the number of elements is between 7 to 11 , when the
Table 4 Deviation between calculated value of visual angle and measured one.

(a) Gothic Style

\begin{tabular}{c|c|c|c}
\hline $\begin{array}{c}\text { adaptation } \\
\text { luminance } \\
\left(\mathrm{cd} / \mathrm{m}^{2}\right)\end{array}$ & $\begin{array}{c}\text { measured } \\
\text { value } \\
\text { (minutes) }\end{array}$ & $\begin{array}{c}\text { calculated } \\
\text { value } \\
\text { (minutes) }\end{array}$ & $\begin{array}{c}\text { deviation } \\
\%\end{array}$ \\
\hline 1000 & 4.73 & 4.44 & 6.1 \\
100 & 5.17 & 5.28 & -2.1 \\
10 & 6.56 & 7.07 & -7.8 \\
1 & 11.91 & 11.31 & 5.0 \\
0.1 & 20.27 & 23.23 & -14.6 \\
0.01 & 43.58 & 64.93 & -49.0 \\
\hline
\end{tabular}

\begin{tabular}{|c|c|c|c|c|c|}
\hline $\begin{array}{l}\text { number } \\
\text { of } \\
\text { elements }\end{array}$ & coefficient & $\begin{array}{l}\text { Gothic } \\
\text { style }\end{array}$ & $\begin{array}{l}\text { Ming } \\
\text { style }\end{array}$ & $\begin{array}{l}\text { Semi- } \\
\text { cursive } \\
\text { style }\end{array}$ & $\begin{array}{c}\text { Pen- } \\
\text { written } \\
\text { style }\end{array}$ \\
\hline \multirow[b]{2}{*}{$4-6$} & A & 2.355 & 2.387 & 2.900 & 2.816 \\
\hline & B & 点 0.4142 & 0.4518 & 0.4689 & 0.4376 \\
\hline \multirow{2}{*}{$7-11$} & A & 3.514 & 3.590 & 3.721 & 3.815 \\
\hline & B & 0.3394 & 0.3485 & 0.3528 & 0.3978 \\
\hline \multirow{2}{*}{$12-19$} & A & 3.518 & 3.805 & 3.903 & 4.320 \\
\hline & B & 0.3546 & 0.3363 & 0.3538 & 0.3468 \\
\hline
\end{tabular}

\begin{tabular}{c|c|c|c} 
(b) Ming Style & \\
\hline $\begin{array}{c}\text { adaptation } \\
\text { luminance }\end{array}$ & $\begin{array}{c}\text { measured } \\
\text { value } \\
\text { (minutes) }\end{array}$ & $\begin{array}{c}\text { calculated } \\
\text { value } \\
\text { (minutes) }\end{array}$ & $\begin{array}{c}\text { deviation } \\
(\%)\end{array}$ \\
\hline 1000 & 4.75 & 4.57 & 3.4 \\
100 & 5.43 & 5.45 & -0.4 \\
10 & 6.88 & 7.34 & -6.7 \\
1 & 12.32 & 11.87 & 3.7 \\
0.1 & 24.15 & 24.71 & -2.3 \\
0.01 & 56.70 & 70.09 & -23.6
\end{tabular}

\begin{tabular}{c|c|c|c}
\hline (c) Semi-Cursive Style & \multicolumn{2}{|c}{} \\
\hline $\begin{array}{c}\text { adaptation } \\
\text { luminance } \\
\left(\mathrm{cd} / \mathrm{m}^{2}\right)\end{array}$ & $\begin{array}{c}\text { measured } \\
\text { value } \\
\text { (minutes) }\end{array}$ & $\begin{array}{c}\text { calculated } \\
\text { value } \\
\text { (minutes) }\end{array}$ & $\begin{array}{c}\text { deviation } \\
\%\end{array}$ \\
\hline 1000 & 4.89 & 4.75 & 2.9 \\
100 & 5.93 & 5.68 & 4.2 \\
10 & 6.88 & 7.68 & -11.6 \\
1 & 13.32 & 12.46 & 6.5
\end{tabular}

\begin{tabular}{c|c|c|c} 
(d) Pen-Written Style & & \\
\hline $\begin{array}{c}\text { adaptation } \\
\text { Iuminance } \\
\left(\mathrm{cd} / \mathrm{m}^{2}\right)\end{array}$ & $\begin{array}{c}\text { measured } \\
\text { value } \\
\text { (minutes) }\end{array}$ & $\begin{array}{c}\text { calculated } \\
\text { value } \\
\text { (minutes) }\end{array}$ & $\begin{array}{c}\text { deviation } \\
(\%)\end{array}$ \\
\hline 1000 & 5.08 & 5.01 & 1.4 \\
100 & 6.27 & 6.13 & 2.2 \\
10 & 8.55 & 8.55 & -6.2 \\
1 & 15.03 & 14.56 & 3.1 \\
\hline
\end{tabular}

Table 5 Coefficients $A$ and $B$ of approximate curve.

number of elements ranges from 4 to 6 and 12 to 19 , the value of $B$ in the Gothic and semi-cursive styles decreases more than that of the Ming style and the pen-written square style.

Table 6 shows the rate of the just readable threshold in the adaptation luminance in cases other than that based upon the measured value at adaptation luminance $100 \mathrm{~cd} / \mathrm{m}^{2}$ of the various styles. When the adaptation luminance changes from $100 \mathrm{~cd} / \mathrm{m}^{2}$ to $1,000 \mathrm{~cd} / \mathrm{m}^{2}$, the just readable threshold changes by about $10 \%$ in the Gothic and Ming 
Table 6 The rate of just readable threshold based on $100 \mathrm{~cd} / \mathrm{m}^{2}$ of each style.

\begin{tabular}{c|l|l|c|c}
\hline $\begin{array}{c}\text { adaptation } \\
\text { luminance } \\
\left(\mathrm{cd} / \mathrm{m}^{2}\right)\end{array}$ & $\begin{array}{l}\text { Gothic } \\
\text { style }\end{array}$ & $\begin{array}{c}\text { Ming } \\
\text { style }\end{array}$ & $\begin{array}{c}\text { Semi-cursive } \\
\text { style }\end{array}$ & $\begin{array}{c}\text { Pen-written } \\
\text { style }\end{array}$ \\
\hline 1000 & 0.91 & 0.87 & 0.82 & 0.81 \\
100 & 1.0 & 1.0 & 1.0 & 1.0 \\
10 & 1.27 & 1.27 & 1.16 & 1.28 \\
1 & 2.30 & 2.27 & 2.25 & 2.44 \\
\hline
\end{tabular}

styles, but in the semi-cursive and pen-written square styles, it changes by about $20 \%$, so the rate of change differs depending upon the style. On the other hand, when the adaptation luminance changes from $100 \mathrm{~cd} / \mathrm{m}^{2}$ in descending series, the just readable threshold tends to change by approximately the same rate for all writing styles.

In previous studies we obtained the approximate curve of the resolvable visual angle and adaptation luminance at $92 \%$ luminance contrast of the visual object;

$$
\theta=\frac{0.3775\left(0.344+L^{1 / 4}\right)^{4}}{L} \text { (minutes) }
$$

By making use of the previously mentioned relation between the character's height and line width i.e., the height of a character is 10.326 times the line width in the Gothic style, we obtain the following formula by multiplying coefficient $A$ of formula (7) by 10.326 .

$$
\theta=\frac{3.8980\left(0.344+L^{1 / 4}\right)^{4}}{L} \text { (minutes) }
$$

Figure 8 shows the relation between the adaptation luminance of each writing form, the just readable threshold, and the formula (8).

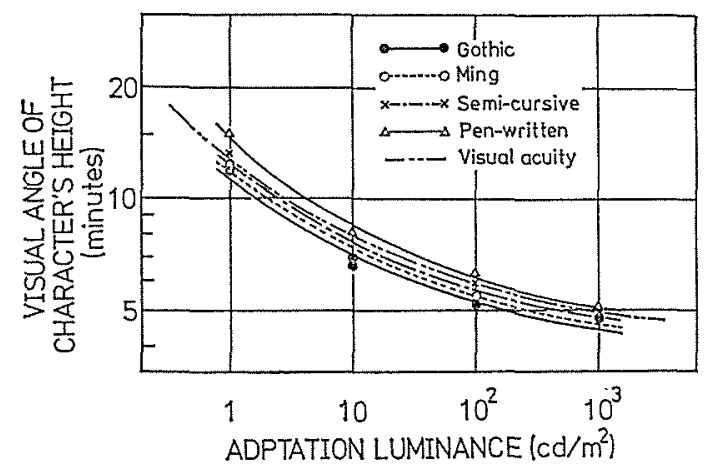

Fig. 8 Visual angle at just readable threshold and adaptation luminance.

The just readable thresholds of Gothic, Ming and semi-cursive style are lower than that of the formula (8), while the break width of Landort ring is corresponding with the character's height of Gothic style.

Table 7 shows the ratios of the calculated height at just readable threshold of the various styles and minimum angle of resolution obtained by formula (7) as a criteria. The ratios of formula (7) and each styles are about constant expect pen-written style; i.e., 9.2 of the Gothic style, 9.5 of the Ming
Table 7 The rate of just readable threshold of each style using that of obtained by formula (7) as criteria.

\begin{tabular}{c|c|c|c|c}
\hline $\begin{array}{c}\text { adaptation } \\
\text { luminance } \\
\left(\mathrm{cd} / \mathrm{m}^{2}\right)\end{array}$ & $\begin{array}{c}\text { Gothic } \\
\text { style }\end{array}$ & $\begin{array}{c}\text { Ming } \\
\text { style }\end{array}$ & $\begin{array}{c}\text { Semi-cursive } \\
\text { style }\end{array}$ & $\begin{array}{c}\text { Pen-written } \\
\text { style }\end{array}$ \\
\hline 1000 & 9.25 & 9.52 & 9.90 & 10.44 \\
100 & 9.26 & 9.56 & 9.96 & 10.75 \\
10 & 9.18 & 9.53 & 9.97 & 11.10 \\
1 & 9.20 & 9.65 & 10.13 & 11.84 \\
\hline
\end{tabular}

style, 10.0 of the semi-cursive style. Then the just readable threshold of the Gothic, the Ming, and the semi-cursive style can be guessed from the formula (7), which is the break width of Landolt ring, by multipling the formula with above constant.

Figure 9 shows a comparison between the just readable threshold of the Ming style obtained in our study and that of the study undertaken by Nakane. ${ }^{5)}$ In Nakane's experiment, using Chinese characters of the Ming style of $85 \%$ luminance contrast and made up of eight strokes, the luminance was gradually increased, and the luminance level when all Chinese characters could be correctly read was recorded. Although the changes in the visual angle of the character's height for the adaptation luminance resemble the results of our study, the visual angle is higher than ours. This is probably because, while we obtained the just readable threshold corresponding to the $50 \%$ threshold, Nakane's study sought the just readable threshold corresponding to the $100 \%$ threshold, and also because of the differences in the luminance contrast of the visual objects. Furthermore, Nakane did not conduct any experiments on luminance in the descending series, so we believe that the results of our study are more appropriate.

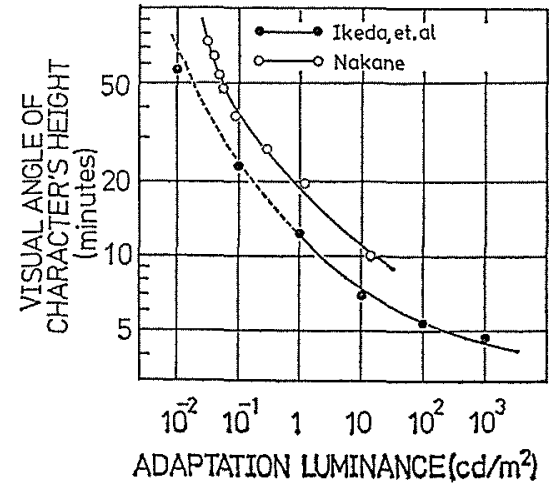

Fig. 9 Comparison between just readable threshold of our study and other's.

\subsection{Just readable threshold and writing style}

The changes in the just readable threshold in accordance with the adaptation luminance are similar in the Gothic, Ming and semi-cursive styles, but in the pen-written square style, the change at 
the just readable threshold increases as the adaptation luminance decreases. Moreover, at the relation corresponding to visual acuity, the curves of changes seem to be similar, but the just readable threshold is considerably lower than in the cases where the line width of the Gothic style is made to correspond to the visual acuity for the Gothic, Ming and semi-cursive styles. The just readable threshold of the pen-written square style practically corresponds to the visual acuity, but it becomes higher where the adaptation luminance is low. In the case of the Ming style, despite the fact that the lines are thinner than those of the Gothic style, the just readable threshold is about the same as that of the Gothic style, which indicates that the overall size of the character is more important than the line width when reading a character. However, as visual acuity corresponds to the size of a character, generally speaking, we believe that a partial identification when attempting to recognize the character will affect the results.

Table 8 The rate of just readable threshold. based on the Gothic style in each adaptation luminance.

\begin{tabular}{c|c|c|c|c}
\hline $\begin{array}{c}\text { adaptation } \\
\text { luminance } \\
\left(\mathrm{cd} / \mathrm{m}^{2}\right)\end{array}$ & $\begin{array}{c}\text { Gothic } \\
\text { style }\end{array}$ & $\begin{array}{c}\text { Ming } \\
\text { style }\end{array}$ & $\begin{array}{c}\text { Semi-cursive } \\
\text { style }\end{array}$ & $\begin{array}{c}\text { Pen-written } \\
\text { slyle }\end{array}$ \\
\hline 1000 & 1.0 & 1.0 & 1.03 & 1.07 \\
100 & 1.0 & 1.05 & 1.15 & 1.21 \\
10 & 1.0 & 1.05 & 1.05 & 1.23 \\
1 & 1.0 & 1.03 & 1.11 & 1.26 \\
\hline
\end{tabular}

Table 8 shows the rate of changes of the just readable thresholds of the various styles using the just readable threshold of the Gothic style at various adaptation luminance as criteria. While the difference between the just readable thresholds of the Gothic and Ming styles is about $5 \%$, the difference between the semi-cursive style and penwritten square style increases as the adaptation luminance decreases. We believe that this is due to the fact that the width of the lines composing the character differs by writing style.

\subsection{Writing style and letters easily misread}

In the previous chapters we studied the Chinese characters which the observer correctly identified, and in this chapter we examined in what way the characters were misread in order to learn how the observer identified the characters.

Table 9 shows examples of Chinese characters whose probability of misreading exceeded $5 \%$.

When we make a comparison of the number of misreading Chinese characters among different writing styles, we find that pen-written square letters are the most frequently misread, while not much misreading can be observed among other styles. We consider that this is because the lines composing the pen-written square letters are thinner than those of other styles, making it difficult to grasp the features of the character. As for the
Table 9 Sample of misreading Chinese characters.

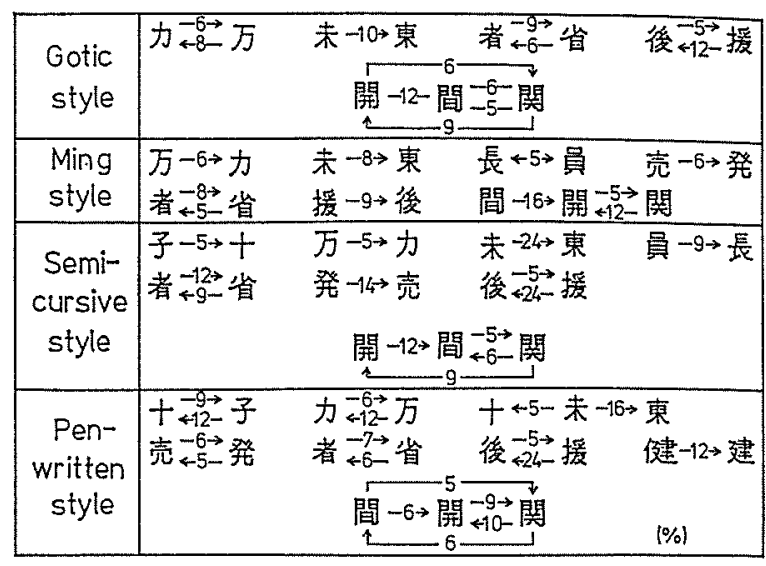

shape of the characters, the following reasons are considered for the misreading of the Chinese characters. Table 10 shows some examples of misreading.

Table 10 Sample of Chinese characters recognized easily and difficult.

\begin{tabular}{|l|l|}
\hline$(1)$ & + 力 万 \\
\hline (2) & 電築 締激 \\
\hline (3) & 間 関 開 援後 \\
\hline
\end{tabular}

(1) When there are similar characters among the 44 characters used as visual objects, even though the number of elements is small, the probability of misreading becomes high.

(2) When there are no similar characters among the 44 objects, characters with easily recognizable feature are easily identified in spite of characters composed with many elements.

(3) Regarding misread characters with many elements, in some cases their features are roughly the same as those of other characters so that they cannot be identified unless their details are examined carefully. In other cases, their structure is complicated and their features cannot be easily grasped.

\section{Conclusion}

In this study we performed visual experiments utilizing Chinese characters of the Gothic, Ming, semi-cursive and pen-written square styles which are frequently used daily as visual objects, and studied the relations among the adaptation luminance, writing styles and just readable threshold. The results obtained are summarized as follows.

(1) The relation between the adaptation luminance and just readable threshold by style are approximated by the following formulas: Gothic Style: 


$$
\theta=\frac{3.514\left(0.3394+L^{1 / 4}\right)^{4}}{L}(\text { minutes })
$$

Ming Style:

$$
\theta=\frac{3.590\left(0.3485+L^{1 / 4}\right)^{4}}{L} \text { (minutes) } \cdots \cdots \cdots \cdots(10)
$$

Semi-Cursive Style:

$$
\theta=\frac{3.721\left(0.3528+L^{1 / 4}\right)^{4}}{L} \text { (minutes) }
$$

Pen-Written Square Style:

$$
\theta=\frac{3.815\left(0.3978+L^{1 / 4}\right)^{4}}{L} \text { (minutes) }
$$

where $\theta$ is the visual angle (minute) of the character's height at the just readable threshold, and $L$ is the adaptation luminance $\left(\mathrm{cd} / \mathrm{m}^{2}\right)$, with in the range from $1 \mathrm{~cd} / \mathrm{m}^{2}$ to $1,000 \mathrm{~cd} / \mathrm{m}^{2}$.

(2) As for the difficulty of recognizing Chinese characters, in the cases of those features are easily grasped, or of no other similar Chinese characters exist, even though they have many elements, identification is easy. On the other hand, even when the number of elements of the characters is small, if there are similar characters, it is easily misread.

Furthermore, in the case of characters composed of many elements which cannot be distinguished from others unless they are examined in detail, and in the case of characters of complicated structure whose feature cannot be easily grasped, their identification is difficult.

(3) In many cases, the Chinese character is identified by first grasp of its overall features and is recognized among those which the observer has learned and memorized. Therefore, in order to identify a Chinese character, first of all it must be of a certain size, and the lines composing the character must be of a certain width in order to distinguish its details, from the correspondence with the approximate curve of visual acuity.

In this study, although we presented each character as a visual object, in our daily lives we identify the letters as sentences based on their combination with other characters and kana (Japanese alphabet) letters. Therefore, it is necessary to continue our studies on the relations between the adaptation luminance and the ease of reading sentences.

\section{References}

(1) Ikeda, K. and Obara, K.: 1980 Conve. Rec. Illum. Engng. Inst. Japan. 13 (1980) 70 (in Japanese).

(2) Ikeda, K. and Obara, K.: 1981 Conve. Rec. Illum. Engng. Inst. Japan. 14 (1981) 71 (in Japanese).

(3) Ikeda, K. and Obara, K.: Technical Report, Television Institute of Engineers of Japan. VVI45-2 (1981) (in Japanese).

(4) Ikeda, K., Noda, K. and Yamaguchi, S.: J. Light Vis. Environ. 4-2 (1980) 22.

(5) Nakane, Y.: Trans. Archite. Inst. of Japan. 229 (1975) 111 (in Japanese).

(6) Ikeda, K., Obara, K. and Noda, K.: 1983 Conve. Rec. Illum. Engng. Inst. Japan. 16 (1983) 133 (in Japanese).

Received 19 Mar. 1984; Revision Received 14 Nov. 1984. 